\section{Doing dental scrap differently}

Simple Refining have been in the dental scrap industry a long time and have seen it all. They won't tell you that they will pay the most, like everybody else. They will say that they have spent years in industry understanding their customer and developing processes that benefit them. With no middleman and an entirely in-house refining process, Simple Refining will get you a payment fast and free within 24 hours. They will send a prepaid, insured envelope to make sure your scrap arrives safely, and provide great value payouts. The Simple Refining team know their customers and go the extra mile to provide a service that sets them apart.

Though their specialism is in Gold
Refinery, Simple Refining don't ignore the other precious metals that are often passed over by on-the-spot refiners. By using their cutting edge XRF technology, Simple Refining are able to pay for platinum, palladium and silver in addition. Their ethos is simple: they can't control the market values of precious metals, but they can control the costs of processing. That's why Simple Refining have added additional metals and removed all outsourcing, middlemen and valuation costs to give their customers the best return.

To work with a refining company that puts customers first, speak to Simple Refining's friendly team today. Call 0800 0323461 or visit www.simplerefining.com.

\title{
Outsource payroll for efficiency in a changing landscape
}

As dentistry adjusts to Brexit, your practice must support smoother workflows during the transition.

Payroll is one area where outsourcing will save money and time, leaving you free to focus on other areas of the business.

Whether your practice is large or small, Wagemate is a specialist payroll service that will manage everything.

When payroll is in the hands of experts, you will get peace of mind that people will be paid accurately and that you are compliant with HMRC's regulations.

Wagemate is dedicated to client relationships and uses the latest technology to deliver a quality service.

In a shifting landscape, choose Wagemate, the premium payroll provider.

To better manage your payroll, contact payroll specialists Wagemate today, tel: 03330 102102 or email info@wagemate.com.

\section{Mindset is the key to practice success in 2021}

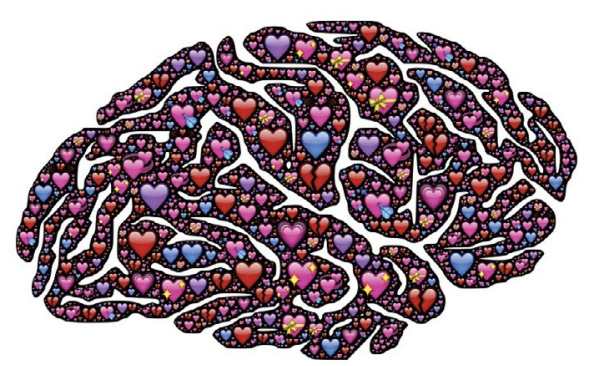

Tracy Stuart of NBS Training is offering dental teams the incredible opportunity to take part in a bespoke '12-month Profitable Dentist Plan', creating a bespoke blueprint formula for success.

Coming out of a challenging year, it is more important than ever before that dentists understand that changes are needed to their team's mindset. If things stay the same, practices will fail to thrive and might not even survive - fact.

Speaking about this unique chance, Tracy said, 'The reason training usually fails is because behaviour doesn't change, and

\section{Facilitate optimal cleaning}

TANDEX produces a range of brushes from the FLEXI interdental brush to UltraSoft options.
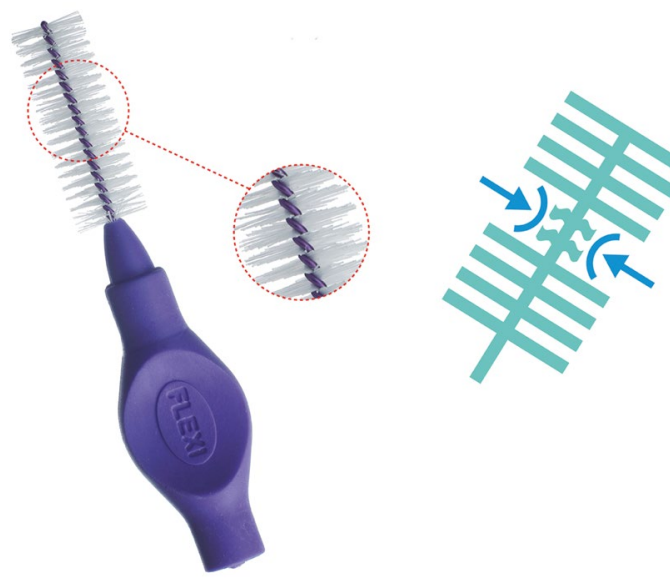

TANDEX is adding international standard (ISO) passage hole diameter (PHD) numbers to its packaging. ISO number defines a range of PHD spaces the brush can be squeezed into without deformation and PHD number defines the specific space the product can be squeezed into.

Inside, each product has a specific colour to make selection of the right size brush for every patient easy and to facilitate optimal cleaning.

TANDEX brushes are quality preventive tools that can help your patients avoid caries; why not try them?

For more information on Tandex's range of products, visit www.tandex.dk. new habits aren't developed. My unique approach to coaching focuses on the team learning to understand how their thoughts hold them back and where a new mindset is needed to make better choices'.

In a nutshell, the training brings about a 'can do' attitude, resulting in practice owners who are amazed at how simple it can be to lead a team when you have Tracy on board.

To book a 30-minute strategy call with Tracy to see how she can help your practice achieve the same incredible results as previous clients, simply email tracy. stuart@nbstraining.co.uk or call 01438 217944. 